\title{
O tradutor intérprete de língua de sinais (TILS) e a política nacional de educação inclusiva em contextos bilíngues para surdos: um estudo da realidade da rede pública estadual paranaense
}

\author{
Danilo da Silva* \\ Sueli de Fátima Fernandes**
}

\section{Resumo}

O tradutor intérprete de língua de sinais (TILS) ganha protagonismo no cenário das políticas educacionais como o profissional, por excelência, que oportunizaria garantir acessibilidade linguística aos surdos em seu processo de educação inclusiva. Em meio a inúmeros avanços no contexto legal, sobretudo a partir da oficialização da língua brasileira de sinais (Libras), em 2002, permanecem lacunas relativas ao direito à educação bilíngue para surdos quanto à real efetividade da atuação desse profissional no território concreto das escolas. Este artigo busca elucidar essa realidade, apresentando o perfil dos TILS que atuam na rede pública estadual da região metropolitana de Curitiba por meio da análise da formação e condiçôes de trabalho desse profissional no contexto das políticas de educaçáo inclusiva. A pesquisa tem abordagem qualitativa e quantitativa apresentando dados coletados em dois contextos investigativos: a consulta oficial à Secretaria de Estado de Educação do Paraná, como órgão gestor da política estadual, e entrevista com tradutores intérpretes de Libras. Foram selecionados vinte e nove municípios para estudo que englobam Curitiba e região pela expressiva população do Estado. Os resultados obtidos permitem uma detalhada análise dos perfil e condiçôes de trabalho dos TILS e apontam que os maiores desafios presentes na realidade concreta das escolas repousam na formação profissional e na proficiência linguística exigida para sua atuação. Desdobramentos desses dois aspectos materializam indicadores na avaliaçáo da qualidade da política nacional de educação inclusiva brasileira em contextos bilíngues para estudantes surdos.

Palavras-chave: Tradutor Intérprete de Língua de Sinais; Educação bilíngue para surdos; Política nacional de educação inclusiva; Rede pública estadual de ensino paranaense.

* Professor da Universidade Federal do Paraná, Curitiba, Paraná, Brasil.

** Professora doutora em Letras/Estudos Linguísticos pela Universidade Federal do Paraná, Curitiba, Paraná, Brasil. 


\section{Sign Language Interpreters/Translators and the National Inclusive Education in Bilingual Contexts for the Deaf: A Study of the Reality of Public Schools in Parana}

\section{Abstract}

Sign language interpreters/translators gain prominence in the educational policies scene as the professionals, par excellence, who provide deaf students with linguistic accessibility in their inclusive educational process. In the midst of numerous advances in the legal context, especially after Brazilian Sign Language (Libras) was officially recognized in 2002, there remain gaps related to the right to bilingual education for deaf people regarding the real effectiveness of those professionals in the actual territory of the schools. This article seeks to elucidate this reality by presenting the profile of sign language interpreters/translators, who work in public schools in the metropolitan region of Curitiba, through the analysis of their training and working conditions in the context of inclusive education policies. The research has a qualitative and quantitative approach, presenting data collected in two research contexts: the official consultation with the Secretary of State of Education of Parana, responsible for state policy, and interviews with Libras interpreters/translators. Twenty-nine cities, comprehending Curitiba and its metropolitan region, were selected for this study for representing the expressive population of the State of Paraná. The analysis of the profile and working conditions of those professionals showed that the greatest challenges present in the concrete reality of the schools rest on the professional training and the linguistic proficiency required for their performance. Developments of these two aspects materialize indicators in the evaluation of the quality of the Brazilian national inclusive education policy in bilingual contexts for deaf students.

Keywords: Sign language interpreters/translators. Bilingual education for deaf people. Brazilian national inclusive education policy. Paraná State Public School.

\section{Palavras iniciais sobre a política nacional de inclusão e a atuação do Tradutor Intérprete de Língua de Sinais (TILS)'}

Este trabalho busca contribuir para melhor compreensão das variáveis envolvidas no processo educacional de surdos, a partir da análise do perfil e condições de trabalho do tradutor intérprete de língua de sinais no contexto nacional das políticas de educação inclusiva, posteriormente a 2008, momento da publicização do documento "Política Nacional de Educação Especial na perspectiva da Educação Inclusiva" (BRASIL, 2008). O texto enuncia como seu principal legado a garantia do direito à educação a grupos que apresentavam diferenças significativas² (AMARAL, 1998), historicamente marginalizados e excluídos do acesso e permanência na escola comum.

$\mathrm{O}$ arcabouço legal constitui um forte instrumento de concretização da garantia de direitos no campo das políticas educacionais atravessado por contradiçóes entre 
o enunciado e o instituído, posto que resulta em uma arena de disputas eivada da tensão permanente entre concepçóes e interesses divergentes quanto ao papel do Estado frente às reivindicaçôes de fraçôes da sociedade civil organizada e de movimentos sociais. A legalizaçấo da língua brasileira de sinais (Libras) como língua nacional das comunidades surdas (Lei Federal 10.436/2002) foi uma conquista fundamental para o reconhecimento da comunidade surda como grupo cultural, relativamente a sua diferença linguística: falar uma língua vernácula brasileira, em condição de minoria.

Em que pesem os avanços políticos legislativos que reconhecem a situação de bilinguismo dos surdos brasileiros "na letra da lei"3, não estão dadas as condiçôes materiais de sua produção histórica como cidadãos bilíngues (FERNANDES, 2014). No campo das políticas educacionais, a garantia desse direito seria dada, se efetivada a incorporação das necessidades linguísticas e culturais diferenciadas dos estudantes surdos no planejamento e implementação de ações político-pedagógicas na educação básica e superior.

No texto da "Política Nacional de Educação Especial na perspectiva da Educação Inclusiva” (BRASIL, 2008) há a priorização do contexto da escola regular na oferta de atendimento para surdos com destaque dos serviços de traduçáo e interpretaçáo:

[...] Para a inclusão dos alunos surdos, nas escolas comuns, a educaçáo bilíngue - Língua Portuguesa/LIBRAS, desenvolve o ensino escolar na Língua Portuguesa e na língua de sinais, o ensino da Língua Portuguesa como segunda língua na modalidade escrita para alunos surdos, os serviços de tradutor/intérprete de Libras e Língua Portuguesa e o ensino da Libras para os demais alunos da escola. (BRASIL, 2008). [destaques dos autores]

A partir desta perspectiva, reiterada em demais documentos oficiais, o tradutor intérprete de língua de sinais (TILS) ganha protagonismo no cenário das políticas educacionais como o profissional, por excelência, que oportunizaria garantir acessibilidade linguística aos surdos em seu processo de inclusão na escola regular.

Por ser uma atividade muito recente, a tradução e interpretação em língua de sinais ainda é cercada de muitos desafios em relação aos aspectos técnico e profissional para o exercício da função, sobretudo no espaço educacional. A legislação atual aponta para a regulamentação da profissão, sem maiores subsídios no trato das questôes linguístico-culturais envolvidas no exercício da profissão.

Pela primeira vez, a questão do perfil profissional foi tratada no Decreto 5626/2005, que aborda o tema em capítulo específico "Da Formação do Tradutor e Intérprete de Libras - Língua Portuguesa", apontando que deve se efetivar por meio de curso superior de Tradução e Interpretação, com habilitação em Libras - Língua Portuguesa. No entanto, nos últimos dez anos, observamos prevalência do critério de exceção de formação em nível médio, por meio de cursos de educação profissional, de extensão universitária, ou promovidos por instituiçôes de ensino superior e instituiçôes credenciadas por secretarias de educação (BRASIL, 2005).

Apenas em 2010, a atuação do tradutor intérprete foi reconhecida nacionalmente pela Lei no 12.319 , em cuja definição profissional destaca-se a "competência 
para realizar interpretação nas duas línguas, de maneira simultânea ou consecutiva, e a proficiência em tradução e interpretação da Libras e da Língua Portuguesa" (BRASIL, 2010). Sobre a formação profissional deliberam-se apenas encaminhamentos em nível médio, omitindo-se a questão da habilitação em nível superior.

Figuram em dois importantes textos legais no cenário nacional em relação à política educacional brasileira - o Plano Nacional de Educação (BRASIL, 2014) e o Estatuto da Pessoa com Deficiência (Lei Federal no 13.146/2015) - a centralidade do TILS como profissional que asseguraria a educação em Libras para surdos no contexto da escola inclusiva. Na estratégia 4.13 (META 4), do PNE 2014-2024 tem destaque a oferta de educação bilíngue efetivada pela ampliação das equipes de profissionais de apoio como os tradutores intérpretes, além de professores de Libras, prioritariamente surdos, e professores bilíngues, já que o plano prevê a oferta também e escolas bilíngues. O Estatuto (BRASIL, 2015) contempla, em alguns de seus artigos, a questáo de acessibilidade linguística pela presença do TILS e normatiza a exigência de ensino médio completo e certificado de proficiência na Libras ${ }^{4}$ para atuar na educação básica; como avanço, citamos a formaçãa superior com habilitação, prioritariamente, em Tradução e Interpretação em Libras, exigida para atuar em cursos de graduação e pós-graduação (BRASIL, 2015).

Essas palavras iniciais sintetizam diretrizes legais que contemplam a especificidade da presença do TILS frente ao reconhecimento da situaçáo de bilinguismo vivenciada pelos surdos brasileiros. Diante da complexidade dos aspectos envolvidos na caracterização do tradutor intérprete, nos interessa investigar algumas das variáveis envolvidas no perfil desse profissional na concretude de sua atuação nas escolas de municípios paranaenses, posto que pouco se conhece sobre os desdobramentos daquilo que é feito em sala de aula na perspectiva da educação inclusiva bilíngue para surdos (LACERDA, 2015).

Isso posto, passemos a detalhar aspectos de nossa investigação que tem o objetivo apresentar o perfil dos TILS que atuam nas escolas de rede pública estadual da Região Metropolitana de Curitiba por meio da análise da formação e condições de trabalho desse profissional no contexto das políticas de educação inclusiva.

\section{Contextualizando o cenário da pesquisa}

A política de educação bilíngue para surdos no estado do Paraná tem início quatro anos antes da aprovação da Lei de Libras, por meio da oficialização da língua brasileira de sinais pela Lei Estadual no 12.095 (PARANÁ, 1998)

O tradutor intérprete de Libras é mencionado nos artigos $4^{\circ}$ e $5^{\circ}$ onde se indica atuação em sala de aula no processo ensino-aprendizagem, desde a Educação Infantil até o ensino superior; seu processo de formaçáo continuada deve ser ofertado pela Secretária de Estado de Educaçáo do Paraná (SEED-PR) e órgáos a ela ligados.

Por ser a escola o principal espaço de atuação do TILS, sua regulamentação é indicada pela SEED-PR, que estabelece normas para reger a profissão em estabelecimentos de ensino da rede pública estadual, por meio da Instrução no 003/2012. 
Esta Instrução normativa reconhece o tradutor intérprete como profissional bilíngue que oferece suporte pedagógico aos estudantes surdos matriculados nas diferentes etapas e modalidades da Educação Básica, sendo responsável pela mediação linguística e comunicação e uso corrente nas situaçóes cotidianos entre o aluno surdo e os membros da comunidade escolar, reafirmando a importância do TILS em contextos educacionais inclusivos.

A pesquisa contemplou abordagem qualitativa e quantitativa e foi realizada em dois contextos investigativos, compreendendo consulta aos dados oficiais disponibilizados pela SEED-PR e entrevista com tradutores intérpretes de Libras que atuam em 29 municípios que compóem a Regiấo Metropolitana de Curitiba ${ }^{5}$, pela expressiva demografia que concentra $64 \%$ do total da população urbana do Estado (mapa da Figura 1).

Figura 1 - Municípios de Curitiba e Região Metropolitana

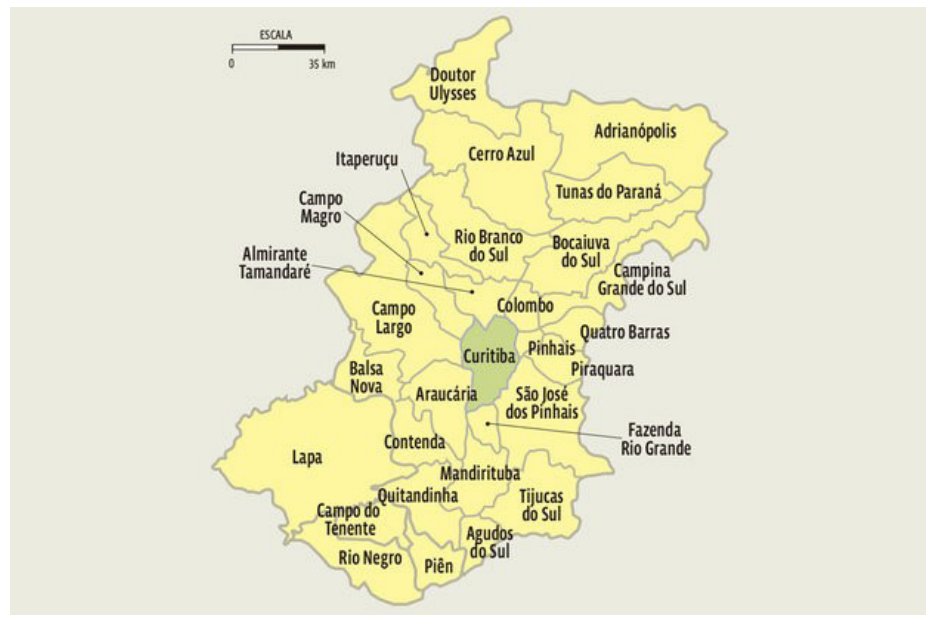

Fonte: https://almanaque.abril.com.br/mapas/Brasil

A pesquisa de campo contemplou TILS que atuam nas escolas estaduais, mediante os seguintes critérios de participação: (i) atuar na rede estadual de ensino; (ii) apresentar vínculo empregatício com a SEED/PR, efetivo ou temporário; e (iii) atuar nos anos finais Ensino Fundamental, Ensino Médio e/ou EJA. A delimitação destas etapas de ensino como universo de pesquisa se fez em razão da concentração do número de profissionais TILS contratados pela SEED-PR nessas etapas da educação básica.

A consulta se deu por meio da aplicação de questionário estruturado como instrumento de coleta de dados, disponibilizado online no Google Docs, composto por 25 questóes com perguntas objetivas (fechadas) e discursivas (abertas). A partir de dados parciais disponibilizados pela SEED-PR e informações dos TILS, por escola, na página de consulta pública do Portal Dia a Dia Educação da SEED, realizamos 
contato por meio de seus perfis no Facebook, solicitando participação e indicação de outros colegas de trabalho. A adesão à pesquisa foi realizada de forma voluntária.

Do total de noventa e três (93) tradutores intérpretes atuantes em escolas estaduais, inicialmente identificados, obtivemos a adesão de quarenta e cinco (45) profissionais, ou seja, uma amostra que correspondeu a $48.4 \%$ dos TILS da região pesquisada.

Os dados foram coletados entre maio e agosto de 2015, organizados em gráficos e analisados à luz de estudos realizados pelos principais pesquisadores que debatem a atuação do intérprete educacional na perspectiva dos Estudos Surdos em Educação (QUADROS, 2004; LACERDA, 2010, 2015; MARTINS, 2009; ROSA, 2005).

O questionário contemplou quatro eixos temáticos, a saber: (I) dados pessoais e socioeconômicos com informaçóes relativas a sexo, faixa etária, raça, faixa salarial, tempo de serviço e escolaridade; (II) formação específica, com informaçóes relativas ao aprendizado de Libras, tipo de certificado para atuação, cursos de capacitação na área; (III) atuação profissional com informaçôes sobre jornada de trabalho, vínculo empregatício; área/nível/local de atuação, número de alunos surdos; tempo de trabalho na área; e por fim, (IV) acessibilidade e inclusão. Neste estudo foram recortados dados coletados nos três primeiros eixos.

\section{O perfil do tradutor intérprete de Língua de Sinais (TILS) na Região Metropolitana de Curitiba}

Os quarenta e cinco sujeitos pesquisados atuam em oito dos vinte e nove municípios selecionados, sendo que 69\% deles trabalha em Curitiba, 13\% em Campo Largo, 5\% em São José dos Pinhais e Campina Grande do Sul e 2\% em Fazenda Rio Grande, Colombo e Lapa.

A maioria das tradutoras intérpretes de Libras participantes é do sexo feminino (73\%); embora não haja pesquisas específicas analisando a predominância da questão de gênero relativas aos TILS, estudos de Martins (2009) Lacerda e Gurgel (2011) corroboram nossos dados de predominância de mulheres, reproduzindo a situação nacional em que o número de professoras é maior em relação ao de professores na área educacional. Com atenção a esse dado, passaremos a usar tratamento de gênero feminino na linguagem referente aos resultados do grupo investigado.

Quanto à idade das TILS, observamos a concentração de 76\% na faixa etária entre 21 a 39 anos, demonstrando ser uma profissão que reúne um grupo de pessoas bastante jovem em atuação. $\mathrm{Na}$ faixa etária de 40 a 59 anos foram $22 \%$, apenas $2 \%$ com até 20 anos. Quanto ao tempo de serviço das TILS, os dados obtidos mostram que $49 \%$ das participantes da pesquisa trabalham de 5 a 10 anos, $33 \%$ há menos de 5 anos e $18 \%$ trabalham há mais de 10 anos. A concentração de $82 \%$ dos profissionais nos últimos dez anos aponta para a coincidência das conquistas dos movimentos surdos por direitos linguísticos na última década que favoreceram o reconhecimento da importância social do TILS no contexto escolar e a ampliação do número de profissionais da área. 
Nossos dados demonstram alto grau de escolarização na formação das participantes, sendo quase metade das TILS (49\%) com especialização, seguida por $42 \%$ com graduação e apenas $9 \%$ com formação em nível médio. O gráfico 1 apresenta os cursos de graduação que foram citados pelas tradutoras intérpretes de Libras:

Gráfico 1: Cursos de graduação dos TILS

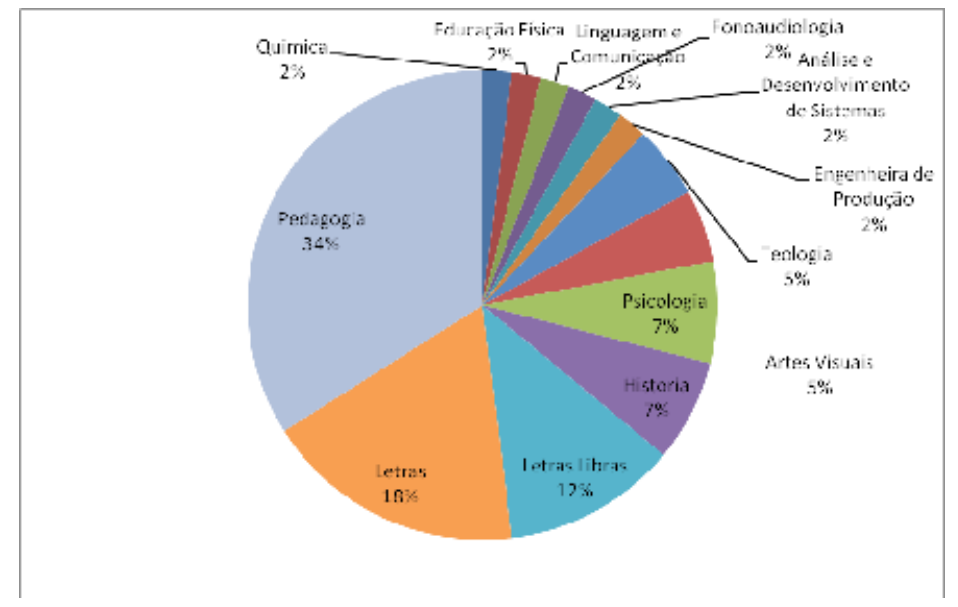

Fonte: Arquivo próprio (2015)

A maioria (34\%) das tradutoras intérpretes têm formação em nível superior no curso de Pedagogia. O curso de graduação em Letras ficou em segundo lugar (18\%), considerando habilitações diversas como Espanhol, Inglês e Literatura. Apenas $12 \%$ das profissionais têm formação em Letras Libras, seja na licenciatura ou bacharelado, o que demonstra a pouca efetividade na implementação de uma diretriz política emanada há 10 anos. A formação da maioria tem grande identidade com a área educacional, favorecendo um trabalho em colaboração com o professor regente de sala de aula.

Em relação aos aspectos da formação específica na área de Libras, o gráfico 2 trata do espaço de aprendizado. A maioria apontou as igrejas (31\%) como espaço principal de aprendizagem, o que aponta forte identidade entre formação-religiăo na trajetória das TILS. O aprendizado em cursos corresponde a 33\% das respostas e $21 \%$ na interação com amigos surdos. Os menores índices estão entre aquelas que aprenderam com familiares surdos (11\%) ou em escolas de línguas (4\%). 
Gráfico 2 Onde Aprendeu Libras?

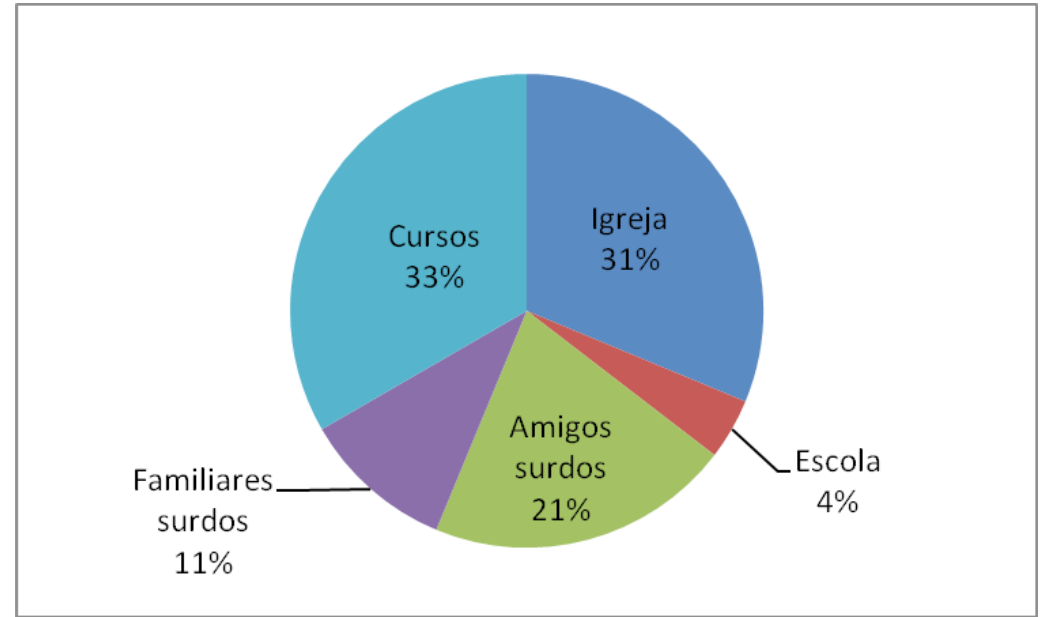

Fonte: Arquivo próprio (2015)

Em relaçáo ao tempo de uso da Libras, 45\% aprendeu no período entre 2006 a 2010. Os demais distribuem-se igualmente entre $22 \%$ que usam Libras há mais de 15 anos e $22 \%$ que aprenderam Libras entre 2001 e 2005 . Houve três participantes que declararam usar Libras há menos de 4 anos e uma única participante $\operatorname{CODA}^{6}$ que adquiriu Libras como primeira língua.

O local e o tempo de uso da Libras interferem significativamente na proficiência do tradutor intérprete, afetando e trazendo prejuízos ao processo de aprendizagem do aluno surdo. A falta de fluência linguística, certamente, contribui para a apropriação do conhecimento e qualidade de informações que chegam aos alunos surdos.

Em relação à comprovação da proficiência ${ }^{7}$ linguística (Prolibras), o Decreto $n^{\circ} 5626 / 2005 /$ Art. 19, indica os profissionais devem apresentar certificaçáo de proficiência em tradução e interpretação (Prolibras) para atuar na área. Além desse certificado, organizaçôes governamentais e não governamentais poderão convalidar conhecimento em exames ou bancas de proficiência. O gráfico 3 detalha os tipos de certificação apresentados pelos tradutores intérpretes à SEED para a contratação. 
O tradutor intérprete de língua de sinais (TILS) e a política nacional de educação inclusiva em contextos bilíngues para surdos: um estudo da realidade da rede pública estadual paranaense

Gráfico 3: Certificação de proficiência de libras

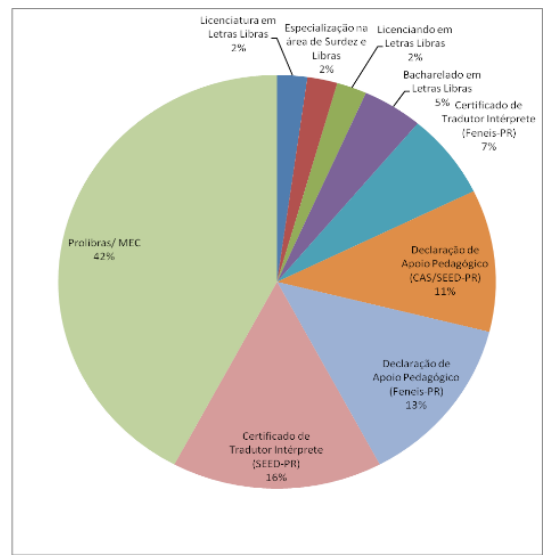

Fonte: Arquivo próprio (2015)

Dentre os certificados declarados pelas TILS para contratação, $42 \%$ refere-se ao "Prolibras no Uso e no Ensino da Libras" e na "Tradução e Interpretação da Libras/Português/Libras", expedidos pelo MEC. Na ausência da formação superior em Tradução e Interpretação, o Prolibras parece ser o instrumento de comprovação de conhecimento linguístico mais utilizado. Depois dele, os Certificados de Tradutor Intérprete emitidos pela SEED-PR aparecem com 16\% e 7\% expedidos pela Federação Nacional de Educação e Integração dos Surdos (Feneis-PR).

O dado mais preocupante foi o grupo de tradutoras intérpretes que atuam apenas com Declarações de Apoio Pedagógico, expedidas pela SEED (11\%) e Feneis $(13 \%)$. Esse documento tem validade de um ano, após o qual a candidata deveria submeter-se novamente à avaliação e é outorgado quando os avaliadores da banca entendem que a profissional ainda não possui fluência linguística para atuar como TILS. Mesmo diante desse indicador de precariedade, ele é aceito pela SEED para atuação, ainda que impliquem "descrédito nos serviços de interpretação; construção de uma imagem não-profissional dos intérpretes; desvalorização da própria língua de sinais e descontinuidade no desenvolvimento da competência tradutória" (PEREIRA e FRONZA, 2010, p.1).

Apenas 5\% declaram ter bacharelado em Letras Libras, formação indicada como preferencial pelo Decreto Federal 5626/2005 para atuação do TILS. A carência de profissionais com formação superior específica na área é uma característica dos participantes de grande relevância, indicando a urgência da criação de novos cursos de Letras Libras - Bacharelado.

Santos (2010) afirma a importância da formação de tradutores intérpretes de Libras no Brasil como marco para constituir mudanças no campo formativo e profissional com formas de institucionalização efetivas políticas e acadêmicas, com respeito à formação especifica. Faz-se extremamente importante aumentar a oferta de vagas de 
bacharelado no ensino superior, como prioridade do governo, especialmente porque a política nacional de inclusão prioriza a presença desses profissionais nas escolas.

O gráfico 4 indica que $60 \%$ dos profissionais não participaram de nenhum curso de capacitação nos últimos três anos.

Gráfico 4: Cursos de capacitação

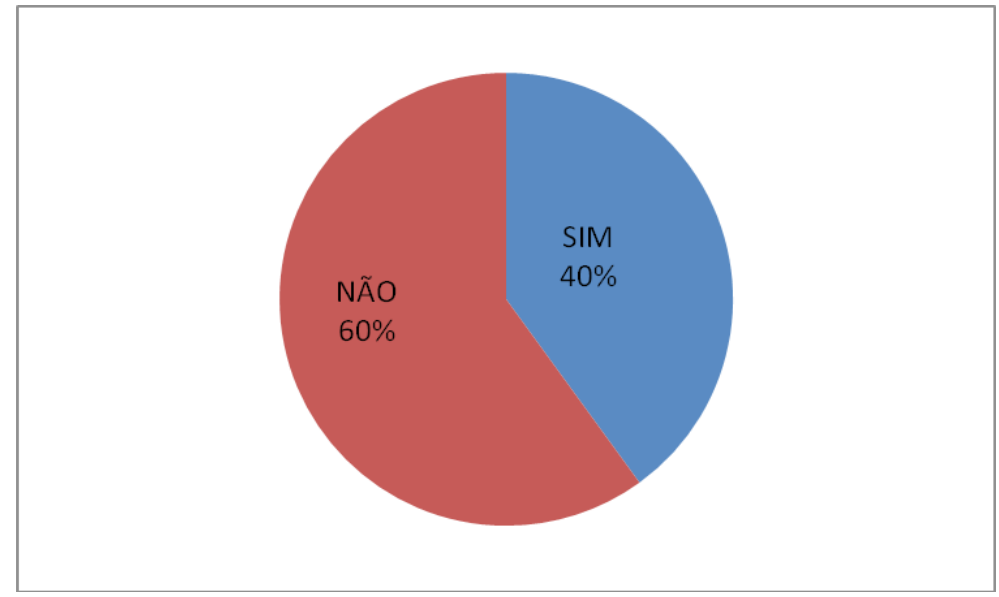

Fonte: Arquivo próprio (2015)

A questão da formação continuada foi um dos assuntos mais mencionados pelas tradutoras intérpretes de Libras nas questóes abertas, indicando uma grande preocupação em relação ao tema. Alegam que as secretárias de educação, instituiçóes públicas ou privadas precisam criar mais projetos voltados para formação específica, já que eles não possuem formação inicial na área.

Albres (2011) aponta estudos de Martins (2009) e Gurgel (2010) que afirmam que a formação dos intérpretes de Libras que atuam na educaçáo é bastante diversificada, seja pelas poucas possibilidades de formação específica para a tradução, seja pela diversidade de saberes, porque a nova profissão e sua regulamentação da profissão são muito recentes.

Segundo Albres (2011), as Diretrizes Nacionais preveem que todos os funcionários de educaçáo devem participar da formação continuada oferecida pelo Estado. A autora apresenta pesquisa em que, dos 43 intérpretes que atuavam nas escolas em 2006, apenas um profissional participava de cursos de capacitaçáo, porque 95\% eram contratados temporariamente e apenas $5 \%$ eram concursados no cargo do professor e considerados como atuando em desvio de funçáo, participavam da capacitaçáo dos professores.

A falta de concursos específicos na área é um problema analisado por Sampaio (1998, p. 87), seu estudo aponta que as secretarias recrutam professores e profissionais, 
habilitados ou não, em caráter temporário. Por não terem prestado concurso público não contam com nenhuma avaliação de sua formação, não recebem benefícios de carreira como o professor efetivo e também não criam vínculo com a unidade escolar.

Nossa análise vincula a oferta precária ou quase inexistente de cursos de formação continuada pela SEED às profissionais à falta de uma política de contratação permanente das tradutoras intérpretes. Quando perguntadas sobre o tipo de vínculo profissional com a rede pública estadual, a maioria das profissionais tem contrato temporário, compreendendo $75 \%$ do total; somente $25 \%$ são servidoras efetivas da SEED e 5\% não responderam (Gráfico 5):

Gráfico 5: Tipo de vínculo empregatício

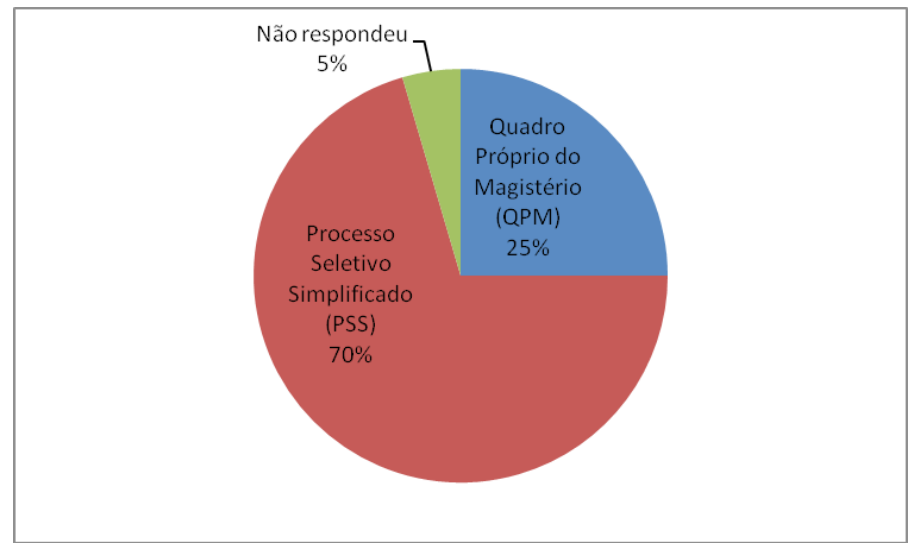

Fonte: Arquivo próprio (2015)

Como comentamos, anteriormente, essa situação expressa o descompromisso do poder público com a carreira desse profissional. $\mathrm{O}$ excesso de rotatividade leva à falta de qualidade no processo de traduçáo interpretação do par linguístico Libras/língua portuguesa, além de não favorecer um vínculo de empatia educacional, também leva à desmotivação na aprendizagem.

Apesar da grande demanda dos profissionais, não há sinalização por parte do governo quanto à oferta de concurso específico voltados à efetivação do TILS no quadro próprio do Estado, como parte do plano de metas da gestão ${ }^{8}$.

Em relação à faixa salarial das participantes, tomamos como unidade de medida comparativa o salário mínimo nacional, em vigor a partir do $1^{\circ}$ do janeiro de 2015, ano da coleta de dados da pesquisa, que era de $\mathrm{R} \$ 788,00$ (setecentos oitenta e oito reais) ${ }^{9}$.

No gráfico 6, observa-se que 69\% declararam faixa salarial entre 2 e 4 salários mínimos ( $\mathrm{R} \$ 1.576$ até 3.152,00); 16\% declararam receber entre 1 e 2 salários ( $\mathrm{R} \$ 788,00$ até 1.575$)$; 9\% situam-se na faixa entre 4 e 6 salários mínimos ( $\mathrm{R} \$$ 
$3.152,00$ até $\mathrm{R} \$ 4.728,00)$ e apenas $4 \%$ ganham entre 6 e 10 salários $(4.728,00$ até $7.880,00)$. 2\% declara faixa salarial acima de 10 salários (acima de $\mathrm{R} \$ 7.880,00$ ).

Gráfico 6: Faixa salarial

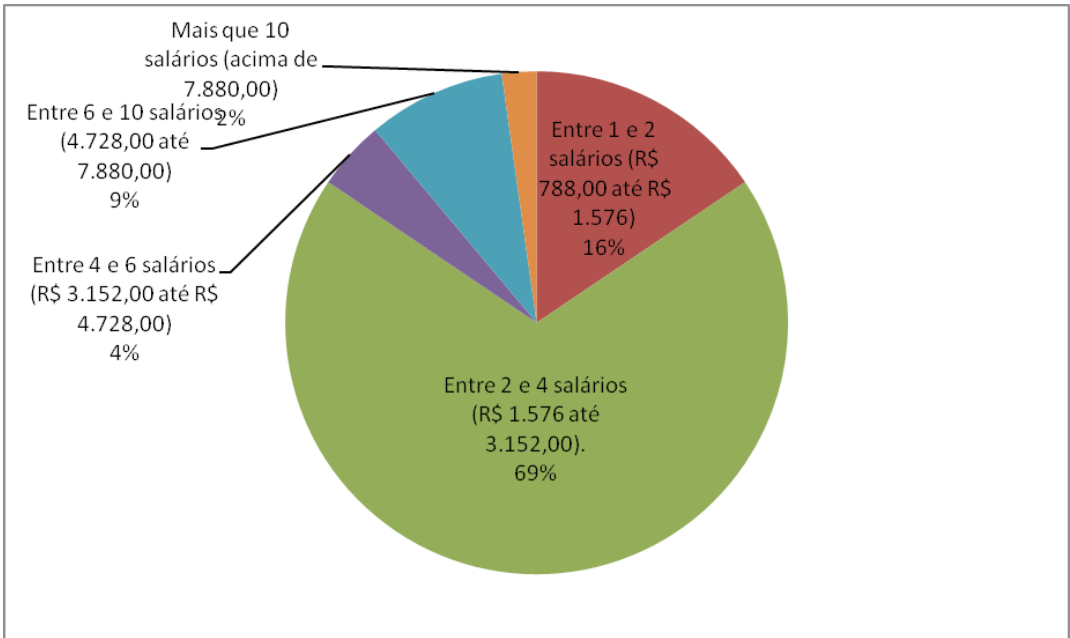

Fonte: Arquivo próprio (2015)

O fato de quase $70 \%$ das TILS receberem entre 2 e 4 salários mínimos demonstra a precariedade no processo de valorização dessas profissionais pelo poder público. Ao fazermos a busca de um parâmetro salarial da categoria, apenas o site da Federação Brasileira das Associações dos Profissionais Tradutores e Intérpretes e Guia -Intérpretes de Língua de Sinais (FEBRATILS $)^{10}$, entidade profissional representativa dos tradutores e intérpretes de línguas de sinais no Brasil traziam tabela salarial, aprovada em outubro de 2015. Há diferenciação para o tipo de tradução e interpretação e a média indicada para 20 horas semanais na área educacional é de $\mathrm{R} \$ 1.400,00$ (mil e quatrocentos reais). Também verificamos o site da $S E E D^{11}$ com tabela salarial atualizada em outubro de 2015, com jornada semanal de 20 horas (formação superior) sendo R \$ 1.279,27 (mil quinhentos noventa e nove reais e nove centavos), excluindose benefícios como vale-transporte. Para 40 horas, o valor é R $\$ 2.558,54$. Os valores praticados são os mesmos dos salários de professores contratados por via do Processo Seletivo Simplificado (contrato temporário).

Comparativamente, um TILS com formação superior a 40h, no Ensino Fundamental e Ensino Médio, receberia R $\$ 2.800,00$ pela tabela FEBRATILS e R\$ $2.558,54$ pela SEED-PR, o que aponta diferença percentual de 8,6\%.

Santos (2012) argumenta sobre a necessidade de mobilização dos profissionais para dar visibilidade e reconhecimento aos TILS, por meio de planos de cargos e salários: 


\begin{abstract}
Relaciona-se isto com a questão dos planos de cargos e salários, que resulta em muitos momentos, em uma atitude de invisibilidade do ser da pessoa do intérprete de Libras e a ausência de mais literaturas que tratem dessa questão histórica com mais propriedade política e educacional, e o fomento de mais organizaçáo política desta categoria na sociedade brasileira. (SANTOS, 2012 p. 2)
\end{abstract}

Buscamos, com esses dados concretos da realidade municipal paranaense, contribuir para a avaliação de resultados da política de educação bilíngue, a partir do conhecimento do perfil desse profissional e de sua configuração no cenário da educação bilíngue para estudantes surdos em processo de inclusão.

\title{
Considerações e apontamentos para futuros estudos
}

Conhecer mais detalhadamente o perfil dos tradutores intérprete de Língua de Sinais (TILS) que ocupa, quase com exclusividade, o papel de principal interlocutor do estudante surdo usuário de Libras, matriculado na escola comum no contexto da inclusão, configura um indicador importante para avaliação da política educacional.

Os dados apresentados neste estudo cumprem esse papel de revelar quem são os profissionais que atuam na rede pública estadual de ensino da Regiáo Metropolitana de Curitiba e apontam inúmeros desafios que a política de educação bilíngue para surdos tem diante de si para se efetivar como um direito.

Os resultados obtidos focalizam para questôes relativas à formação profissional que acarretam precariedade na proficiência linguística dos TILS, interferindo na qualidade do conhecimento dispensado a alunos surdos em salas inclusivas. Soma-se a essa questão, a desvalorização profissional indicada pelos baixos salários, ausência de políticas de contratação permanente que viabilizassem a instituição de planos de carreira e de formação continuada. Esses elementos materializam carências e adversidades na oferta da educaçáo de surdos no cenário local, contribuem para indicadores de avaliação da qualidade da política nacional de educação inclusiva brasileira.

O fato de a Libras ser uma língua recentemente oficializada, tendo sido proibida por muito tempo na escola, requer um amplo processo de planejamento linguístico para sua difusão na sociedade, identificando-a como fator positivo de produção cultural das comunidades surdas. Como afirma Andreis-Witkoski (2011, p.192) "somente o uso e a ocupação de espaços sociais poderão conferir a Língua, como a toda e qualquer língua viva cada vez e maior riqueza de expressáo do mundo real e pensado".

Nesse sentido, a preocupação principal da comunidade surda é que o tradutor interprete receba uma formação que o habilite a atuar com mais qualidade e mais fluência nas duas línguas, com boa execução de tradução e interpretação, produzindo as estruturas gramaticais particulares de cada língua sem interferência.

Muitos TILS se preocupam com a qualidade da fluência em Libras, mas, sem formaçáo continuada, a performance dos TILS fica comprometida e desconectada das inovaçôes linguísticas da comunidade surda. São necessárias oportunidades de interação dos profissionais da escola com profissionais fluentes, com experiência na área de tradução e interpretação de Libras para transmitir teorias, efetuar trocas de conhecimentos e vivências.

Revista Educação Especial | v. 31 | n. 60 | p. 35-50 | jan./mar. 2018

Santa Maria 
A proficiência em Libras é essencial porque o profissional desenvolve a mediação pedagógica, com domínio linguístico e lexical do campo em que vai atuar, também nos cursos de formação de intérpretes incluem a discussão sobre a construção de sentidos e as estratégias de tradução e interpretação.

A falta de quadros profissionais com formação específica na área de Letras Libras/Bacharelado, impóe políticas públicas de ampliação de vagas nas instituições de ensino superior públicas, com urgência, especialmente porque a política nacional de inclusão prioriza a presença desses profissionais em salas de aula.

A identificação da carência/precariedade da formação profissional das TILS que estão atuando e "supostamente" promovendo a inclusão de estudantes surdos nos anos finais do ensino fundamental/médio/EJA suscitam inúmeros questionamentos sobre sua efetividade para garantir a oferta da educação bilíngue nas escolas, tal como enunciado no conjunto de textos legais que sintetizam a política educacional para surdos, na atualidade.

Quais são as competências requeridas à formação de um intérprete que atua no contexto escolar em anos finais do ensino fundamental e ensino médio, em contato com crianças e jovens que estão consolidando seu processo de aquisição/aprendizagem da Libras? Quais seriam as funções e atribuiçóes desempenhadas por TILS que atuam como corregentes em se tratando de sala de aulas inclusivas. Em que medida sua atuação restringe-se ao universo estritamente linguístico dos domínios discursivos da Libras/língua portuguesa e abrangeriam funções pedagógicas, para além da interpretação simultânea em sala de aula?

O fato de mais de $90 \%$ dos TILS que atuam na Região Metropolitana de Curitiba não serem do quadro permanente da SEED revela descaso com a qualidade e o direito à educação bilíngue de qualidade, amplamente assegurada no discurso oficial. Concursos públicos para efetivar a função e carreira própria de tradutores e intérpretes de Libras não deveriam constituir prioridade em um cenário de políticas inclusivas?

O avanço e consolidação das conquistas garantidas nos textos legais pelas comunidades surdas brasileiras dependem da ampla mobilização e engajamento de setores que possam aprofundar esse debate.

Nossos apontamentos incidem sobre a contribuição que pesquisas acadêmicas como esta podem trazer ao campo da política educacional evidenciando lacunas no campo do direito à educação por meio da explicitação da realidade local que apontam para problemas e temas de pesquisa a serem investigados, intencionando contribuir com os eixos de sustentação da política de educação inclusiva voltados ao direito da educação bilíngue para surdos.

\section{Referências}

ALBRES, Neiva de Aquino. A formaçáo de intérpretes de Libras para um serviço da Educaçáo Especial. O que os currículos de especialização em Libras tem nos revelar. Londrina: Encontro da Associação Brasileira de Pesquisadores em Educação Especial, novembro de 2011. 
O tradutor intérprete de língua de sinais (TILS) e a política nacional de educação inclusiva em contextos bilíngues para surdos: um estudo da realidade da rede pública estadual paranaense

AMARAL, Ligia Assumpção. Sobre crocodilos e avestruzes: falando de diferenças físicas, preconceitos e sua superação. In: AQUINO, J. G. (org.). Diferenças e preconceito na escola: alternativas teóricas e práticas. São Paulo: Summus, 1998, 5 a edição, p. 11-30.

ANDREIS-WITKOSKI. Sílvia. Educaçáo de surdos e preconceito: bilinguismo na vitrine e bimodalismo precário no estoque. 2011. 255 folhas. Tese de doutorado em Educação. UFPR, Curitiba, 2011.

BRASIL. Lei 10.436, de 24 de abril de 2002. Dispõe sobre a Língua Brasileira de Sinais (LIBRAS) e dá outras providências.

BRASIL. Decreto no 5.626, de 22 de dezembro de 2005. Regulamenta a Lei no 10.436, de 24 de abril de 2002, que dispóe sobre a Língua Brasileira de Sinais - Libras.

BRASIL. Política Nacional de Educaçáo Especial na Perspectiva da Educaçáo Inclusiva. Documento elaborado pelo Grupo de Trabalho nomeado pela Portaria Ministerial no 555, MEC/SEESP, de 5 de junho de 2008.

BRASIL. Lei $n^{\circ}$ 12.319, de $1^{\circ}$ de setembro de 2010. Regulamenta a profissão de Tradutor e Intérprete da Língua Brasileira de Sinais - LIBRAS.

BRASIL. Decreto $\mathbf{n}^{\circ}$ 8.381, 29 de dezembro de 2014. Dispốe sobre o valor do salário mínimo para primeiro de janeiro de 2015.

BRASIL. Lei no 13.005, de 25 de junho de 2014. Aprova o Plano Nacional de Educaçáo-PNE e dá outras providências, 2014.

BRASIL. Lei no 13.146, de 6 de Julho de 2015. Institui a Lei Brasileira de Inclusão da Pessoa com Deficiência (Estatuto da Pessoa com Deficiência).

FERNANDES, Sueli. Avaliaçấo escolar e educação bilíngue para surdos: a questâo das línguas na política de inclusão. São Carlos-SP: UFSCAR. In: ALMEIDA, Maria Amelia; MENDES, Eniceia. G. (Org.). A escola e o público-alvo da educaçáo especial: apontamentos atuais. São Carlos: Marquezine \& Manzini: 2014.

GURGEL, Taís Margutti do Amaral. Práticas e formação de tradutores intérpretes de língua brasileira de sinais no ensino superior. Tese. (Doutorado em Educação). Universidade Metodista de Piracicaba. Piracicaba-SP. 2010

IBGE. Instituto Brasileiro de Geografia e Estatística. Censo Demográfico 2010. Disponível em: <http://www. sidra.ibge.gov.br/cd/cd2010CGP.asp?o=13\&i=P> Acesso em 25 mar 2016.

LACERDA. Cristina Broglia Feitosa de; GURGEL, Taís Margutti do Amaral. Perfil de tradutores-intérpretes de Libras (TILS) que atuam no ensino superior no Brasil. Marilia: Revista Brasileira de Educaçáo Especial, 2011, v.17

LACERDA, Cristina Broglia Feitosa de. Tradutores e intérpretes de Língua Brasileira de Sinais: formação e atuação nos espaços educacionais inclusivos. Cadernos de Educaçáo, v. 36, n. 1, p. 133-53, 2010.

LACERDA, Cristina Broglia Feitosa de. Intérprete de Libras em atuação na educaçáo infantil e no ensino fundamental. Porto Alegre: Editora Mediação, 2015. $6^{\circ}$ Edição

MARTINS, Diléia Aparecida. Trajetórias de formação e condiçóes de trabalho do intérprete de libras em instituiçóes de Educaçáo Superior. 2009. 135f. Dissertação de Mestrado em Educaçấo - Pontifícia Universidade Católica de Campinas, Campinas, 2009.

PARANÁ. Lei no 12.095, de 11 de março de 1998. Reconhece oficialmente, pelo Estado do Paraná, a linguagem gestual codificada na Língua Brasileira de Sinais - LIBRAS e outros recursos de expressão a ela associados, como meio de comunicação objetiva e de uso corrente.

PARANÁ. Instruçáo no 003/2012 - SEED/SUED Estabelece normas para atuação do profissional tradutor e intérprete de Língua Brasileira de Sinais-Libras/Língua Portuguesa - TILS nos Estabelecimentos de Ensino da Rede Pública Estadual.

PEREIRA, Maria Cristina Pires; FRONZA, Cátia de Azevedo. Estudo sobre a proficiência lingüística do intérprete de libras. In: Cadernos do Congresso Nacional de Linguística e Filologia (CNLF). 2010.

QUADROS, Ronice Müller. $\mathbf{O}$ tradutor e intérprete de língua brasileira de sinais e língua portuguesa. Secretaria de Educação Especial; Programa Nacional de Apoio à Educaçáo de Surdos - Brasília: MEC; SEESP, 2004.

ROSA, Andrea da Silva. Entre a visibilidade da traduçáo da língua de sinais e a invisibilidade da tarefa do intérprete. Campinas, Dissertação (Mestrado em Educação) - Universidade Estadual de Campinas, 2005. 
SAMPAIO, Maria Das Mercês Ferreira. Um gosto amargo de escola: relação entre currículo, ensino e fracasso escolar. São Paulo: EDUC, 1998.

SANTOS. Ozivan Perdigão. Travessias históricas do tradutor; intérprete de Libras: de 1980 a 2010. Belém: Revista do Difere, v. 2, n.4, dez/2012

SANTOS, Silvana Aguiar. Tradução e interpretaçáo de língua de sinais: deslocamentos nos processos de Formação acadêmica e profissional. Cadernos de Traduçáo. Florianópolis, v. 2, n. 26, p. 145-164, 2010.

\section{Notas}

${ }^{1}$ Neste trabalho, utilizaremos a denominaçâo Tradutor Intérprete de Língua de Sinais (TILS), preferencialmente, apesar de reconhecermos outras denominaçóes que são usualmente empregadas como tradutor intérprete de Libras, intérprete, entre outras.

2 Amaral (1998, p. 13) apresenta o conceito de "significativamente diferente" ou "diferença significativa" como sinônimo de deficiente/deficiência, os quais pressupôem "a eleiçấo de critérios, sejam eles estatísticos (moda e média), de caráter estrutural/funcional (integridade de forma/funcionamento), ou de cunho psicossocial, como o do tipo ideal".

${ }^{3}$ Lei Federal 10436/2002; Decreto Federal 5626/2005, Política Nacional de Educaçăo Especial na perspectiva da Educaçáo Inclusiva (2008), Lei 12139 (2010), Lei 13146/2015.

${ }^{4}$ Exame Nacional para Certificação de Proficiência no uso e no ensino de Libras e para Certificação de Proficiência na tradução e interpretação de Libras/Português/Libras.

${ }^{5}$ A Regiấo Metropolitana possui 3.168.980 (IBGE, 2010). Por divisão político-administrativa da SEED, seus 29 municípios estão divididos em Núcleos Regionais de Educação, sendo: NRE de Curitiba, NRE da Área Metropolitana Norte (Adrianópolis, Almirante Tamandaré, Bocaiúva do Sul, Campina Grande do Sul, Cerro Azul, Campo Magro, Colombo, Doutor Ulysses, Itaperuçu, Pinhais, Piraquara, Rio Branco do Sul, Quatro Barras e Tunas do Paraná) e NRE da Área Metropolitana Sul (Agudos do Sul, Araucária, Balsa Nova, Campo do Tenente, Campo Largo, Contenda, Fazenda Rio Grande, Lapa, Mandirituba, Piên, Quitandinha, Rio Negro, São José dos Pinhais e Tijucas do Sul).

${ }^{6}$ Termo utilizado para se referir a filhos de pais surdos, do inglês Children of Deaf Adult (CODA).

${ }^{7}$ Segundo Pires e Fronza (2010) "a proficiência linguística abrange um conjunto de competências que representam os aspectos motores e temporais da fluência, o conhecimento metalinguístico e gramatical e o uso apropriado desse conhecimento, com outros falantes, em contexto sociocultural".

${ }^{8}$ Gestăo Carlos Alberto Richa (2011-2015)

${ }^{9}$ Conforme o Decreto no $8.381 / 2014$.

${ }^{10}$ http://www.febrapils.com.br/2016/01/tabela-de-honorarios.html

${ }^{11}$ http://www.educacao.pr.gov.br/arquivos/File/pss/pss2015/tabela_vencimentos_pss_outubro2015.pdf

\section{Correspondência}

Danilo da Silva - Universidade Federal do Paraná, Setor da Ciências Humanas. Rua Amintas de Barros, 415. Centro. CEP: 80062-981. Curitiba, Paraná, Brasil.

E-mail: danilo.silva@ufpr.br - suelifernandes@ufpr.br

Recebido em 21 de novembro de 2016

Aprovado em 31 de maio de 2017 